\title{
OFICINAS DE FUTEBOL COMO INSTRUMENTO DE PROMOÇÃO DO AUTOCONTROLE ENTRE PESSOAS QUE CONSOMEM CRACK
}

\author{
SOCCER WORKSHOPS AS AN \\ INSTRUMENT TO PROMOTE SELF- \\ CONTROL AMONG PEOPLE WHO \\ CONSUME CRACK
}

Ygor Diego Delgado Alves

antropologiaygor@yahoo.com.br

Antropólogo graduado e mestre pela Pontificia Universidade Católica de São Paulo; doutor em Antropologia pela Universidade Federal da Bahia; pós-doutorando em Saúde Coletiva pela UNIFESP, onde é bolsista PósDoutorado Júnior pelo $C N P Q$.

Orcid: http://orcid.org/0000-0002-6730-3255

Pedro Paulo Gomes Pereira

pedropaulopereira@hotmail.com

Livre Docente pela Universidade Federal de São Paulo (2013). Professor Associado da Universidade Federal de São Paulo. Professor do Programa de Pós-Graduação em Saúde Coletiva da Universidade Federal de São Paulo.

Orcid: https://orcid.org/0000-0002-0298-2138

\section{RESUMO}

Neste artigo, fruto de pesquisa etnográfica realizada entre os anos de 2012 - 2014, pudemos verificar que no jogo de futebol, um enfrentamento entre equipes submetidas à mesma regra e com um juiz responsável por interpretá-la a cada jogada e distribuir as punições, a luta aberta entre jogadores está fora das possibilidades permitidas pelas regras adotadas e tanto quanto existe uma barreira a enquadrar o jogo e a defendê-lo das influências externas irá se desenvolver através dos treinos e jogos em campeonatos, uma couraça protetora no jogador contra o extravasamento de certas emoções. Isto possibilita maior autocontrole em pessoas que consomem crack.

Palavras-chave: Crack. Etnografia. Futebol.

\begin{abstract}
In this article, which results of an ethnographic research conducted between the years of 2011 and 2014, we could verify that in soccer games, a confrontation between teams subject to the same rule and with a judge responsible for interpreting it at every move and distributing punishments, the unregulated competirion between players is out of the possibilities allowed by the adopted rules and as much of a barrier there is to frame the game and defend it from external influences that will develop, through training and games in championships, a protective armor in the player against the extravasation of certain emotions. This enables greater self-control in people who consume crack.
\end{abstract}

Keywords: Crack. Ethnography. Soccer. 


\section{INTRODUÇÃO}

Este artigo pretende mostrar, a partir da descrição proporcionada pela pesquisa etnográfica realizada entre os anos de 2012 - 2014, como o futebol, e particularmente os sentimentos de equipe possibilitados pela absorção no jogo, o enquadramento e as regras de irrelevância, dá oportunidade para o trabalho do orientador socioeducativo - aqui designado pela denominação utilizada pelos nossos interlocutores "professor" ou técnico - abrir espaço para um aumento do autocontrole por parte dos jogadores sobre seu padrão de uso de álcool, crack e outras drogas devido a mudanças em sua estrutura de vida. ${ }^{1}$

Cinco jogadores uniformizados de cada lado e um juiz, numa quadra coberta de futebol de salão. Nas laterais do campo, o técnico grita frases de orientação tática e técnica: "Sai da marcação"; "Vem, vem, vem"; "Espalha aí, vamos jogar aberto"; "Ó a marcação aí, ó”. Determinado momento, resolve orientar de modo individualizado: "Levanta a cabeça, Paraná"; em outro, de modo um pouco mais incisivo: "Vamos fazer gol, caralho!". Nada que não possa ser encontrado em uma escolinha de futebol ou em um colégio durante a aula de educação física. Porém quem admirasse a partida poderia perceber alguns aspectos intrigantes no desenrolar das jogadas. O primeiro deles é o fato do técnico ser responsável por ambas equipes em campo, durante este jogo/treino. Até esse ponto, nada haveria de tão extraordinário, mas, talvez a presença de um jogador trajando boné, óculos escuros e fones de ouvido fosse algo a despertar maior curiosidade. Mais ainda, se esse jogador perdesse a oportunidade de marcar um considerável número de gols por, aparentemente, procurar dar a eles um tom a mais de brilho, um toque a mais de plasticidade, de beleza e mesmo certo "quê" de comicidade, isso causaria ainda mais interesse no observador. Esse jogador é Paraná, constantemente advertido pelo "professor" quanto a sua postura corporal. Em breve veremos porque Paraná nos é tão importante.

Ainda assim, a singularidade desta partida está longe de ser desvendada. Para tanto, precisaríamos fazer um duplo movimento. Um para fora e outro no sentido inverso. O primeiro nos mostraria o contexto no entorno da quadra de futebol e o segundo, quem eram aqueles jogadores minutos antes do início da partida e como estão após seu término. A quadra se situa em um centro de acolhida conveniado com a Prefeitura do Município de São Paulo, no bairro do Bom Retiro e é cercada por símbolos do cristianismo católico. Paraná é um ex-"pai de rua", termo conotativo daqueles responsáveis por algum tipo de atividade, muitas vezes ilegal, no ambiente das ruas e, geralmente, com sua autoridade imposta pela violência.

Ainda não é esse o aspecto capaz de causar maior impressão naquele disposto a aproximar-se um pouco mais do cotidiano dos tais jogadores. Um observador atento teria oportunidade de saber do uso cotidiano de crack pela quase totalidade dos envolvidos, inclusive Paraná. Assim como, por mais de uma década, também pelo técnico ou professor, um ex-usuário de crack e ex-morador de rua na região do centro da cidade de São Paulo, conhecida como Cracolândia. Um observador participante, caso desejasse mostrar suas habilidades em campo, ou simplesmente divertir-se em uma partida/treino de futebol com 10 minutos de duração ou dois gols marcados pela mesma equipe, correria o risco de sentir nas próprias canelas o ímpeto e vontade de vencer presente dentro daquelas quatro linhas. Nas palavras de Johan Huizinga (1996, p. 58): "O que é primordial é o desejo de ser melhor que os outros [...] o principal é ganhar". 


\section{ESTUDOS ANTROPOLÓGICOS SOBRE O CONSUMO DO CRACK E SEUS CONTEXTOS}

A pesquisa de Da Silva (2000) intitulada Mulheres da Luz: uma etnografia dos usos e preservação no uso do "Crack" foi pioneira e pode ser considerado um marco na mudança de foco dos usuários de drogas injetáveis (UDIs) para consumidores de cocaína por outra via, a fumada a partir da pedra de crack. Após esse trabalho, que data do ano de 2000, temos a etnografia de Larissa Pelúcio $(2005$, p. 231) que também irá versar sobre territórios de prostituição. Porém a pesquisadora descreverá a construção do que chama de "ser travesti", na cidade de São Carlos, em que aparecerá o uso do crack entre outras substâncias disponíveis para "se colocar" - usar drogas.

Entre os anos de 2002 e 2005 foram realizados, no Brasil, cinco projetos piloto de redução de danos entre usuários de crack e todos enfrentaram, de modo mais ou menos acentuado, grandes dificuldades. Estas foram atribuídas pela pesquisadora Andrea Domanico a forma dos financiamentos, marcada pela "ditadura dos projetos", e ao elevado grau de exclusão dos usuários imposto pelo "pânico moral" (DOMANICO, 2006, p. 9) em torno do crack.

Relatos etnográficos sobre o uso do crack são produzidos por Rui (2006) na cidade de Campinas, próxima a capital paulista, entre os adolescentes em situação de rua, na forma do "pitilho" cigarro misturado com crack. Frúgoli Jr. (2008, p. 2) cita a existência de "tráfico e consumo de crack em vários espaços públicos" do bairro da Luz, centro da cidade de São Paulo. Raupp e Adorno (2010) realizam uma etnografia, esta sim, voltada especificamente a descrição das relações entre o contexto social vivido na Cracolândia e o padrão de uso compulsivo do crack. Introduzem, em Raupp (2011), o conceito de circuito - retirado de Magnani (2007), e utilizado anteriormente na pesquisa de Fernandez (2007, p. 159) sobre os "circuitos do pó" - em busca de descrever o exercício da prática de fumar crack e os equipamentos, estabelecimentos e espaços relacionados com essa prática. Assim como a observação da sociabilidade e do manejo de códigos em um território psicotrópico (FERNANDES; PINTO, 2004): local, reconhecido pela função desempenhada, em que se vive em torno da venda e consumo de substâncias ilícitas. Conceito também presente em Gomes e Adorno (2011, p. 584) que procuram compreender a trajetória do usuário até tornar-se "noia", aqui percebido "como aquele que desrespeita as normas sociais e os parâmetros éticos em busca da pedra de crack, é visto com desconfiança e não consegue estabelecer relações de outra forma com as pessoas". Dos territórios psicotrópicos para as territorialidades itinerantes. Frúgoli Jr. e Cavalcanti (2013) tratam das dinâmicas espaciais urbanas presentes nas chamadas cracolândias das cidades do Rio de Janeiro e São Paulo.

Do noia ao abjeto, Taniele Rui (2012) fala de como a relação com o crack, sob certa circunstância considerada pela autora como extrema e radical, pode ser produto e produtora de uma corporalidade abjeta, que radicaliza a alteridade. Isso viria justificar intervenções de caráter tanto repressivo quanto assistencial, respectivamente, a eliminação e a recuperação. Na coletânea Crack: contextos, padrões e propósitos de uso, a etnografia de Luana Malheiro (2013), fortemente influenciada por Jean Paul Grund (1993), autor que pesquisou o uso de heroína e cocaína em Roterdã, complexifica os termos atribuídos aos consumidores da droga. Que na região do centro histórico da cidade de Salvador se apresentam sob a forma de três tipos distintos: o sacizeiro, o usuário e o patrão. O primeiro corresponderia ao neófito, que fuma compulsivamente e deixa transparecer estar sob efeito da droga; o segundo teria maior experiência e autocontrole sobre seu padrão de uso, recusando-se, no mais das vezes, estar 
na companhia dos sacizeiros; o último tipo, o patrão, é dedicado ao comércio da substância e muito dificilmente dela fará uso compulsivo.

Mais uma etnografia com olhar voltado para o contexto de uso do crack e sua influência sobre as práticas de uso, o trabalho de Vallim, Zaluar e Sampaio (2015), percorre as seguintes cenas de uso: o bairro da Glória; as favelas de Manguinhos e Jacarezinho; e a estação Central do Brasil. Sob forte influência dos trabalhos de Zinberg (1984) e Grund (1993), o estudo irá se dedicar a: (1) descrição das cenas; (2) sua influência sobre os efeitos da droga; e (3) descrição dos rituais, símbolos e sanções sociais que venham a constranger o consumo do crack a padrões aceitáveis pelos pares.

O contexto do consumo do crack também será objeto de exposição na pesquisa de Alves (2016). O autor irá se dedicar a delinear a parafernália, as técnicas e rituais de uso e os efeitos percebidos. Selma Lima da Silva (2017), que no ano de 2000 havia realizado estudo pioneiro relacionando prostituição e consumo do crack no bairro da Luz, em São Paulo, expõe os diferentes padrões de controles informais e de autocuidado, a partir de narrativas obtidas nas cidades de Lisboa e, novamente, na capital paulista. Autocuidado este que pode ser impulsionado ou obstaculizado por certas políticas públicas como são os programas a atuar na Cracolândia. Em Medeiros (2014), podemos verificar como as respostas institucionais costumam se prender a imagens negativas construídas socialmente. Também o quanto estas imagens contribuem negativamente no processo terapêutico levado à frente por equipes profissionais na cidade de Belo Horizonte.

Deborah Fromm (2017), em sua pesquisa etnográfica, penetra na institucionalidade presente na cena de uso do bairro da Luz, através do acompanhamento dos percursos de três personagens pelos programas Cristolândia, De Braços Abertos (doravante DBA) e Recomeço. A autora busca chamar atenção para as estratégias de sobrevivência no cotidiano frente ao que acredita serem tentativas de pôr fim à Cracolândia. O DBA também será objeto da análise de Nasser (2018), a partir dos percursos de uma jovem que não foi aceita no programa. Souza (2015) teve contato com o pessoal de ponta da saúde e assistência e, principalmente, com guardas municipais, dessa forma faz etnografia do trabalho desses agentes de segurança a partir da implantação do DBA. Tem um olhar para o drama diário vivido pelos agentes públicos e para as consequências advindas dos procedimentos adotados na diferenciação entre usuários e traficantes. Uma descrição mais pormenorizada do DBA pode ser encontrada em Alves (2017), desde as articulações entre secretarias municipais para dar início ao programa, até uma descrição do seu modo de funcionamento. É também do mesmo autor uma crítica ao conceito biomédico de dependência a partir do que designa como uma antropologia do "fluxo", como são chamados os movimentos e percursos em torno do consumo do crack, na Cracolândia (ALVES; PEREIRA, 2019). Aos percursos em torno do consumo da droga, soma-se, na etnografia de Luana Malheiro (2019), a descrição da violência racial, de classe e de gênero. A autora aponta, em seu trabalho com as mulheres que fumam crack no centro velho de Salvador, como a construção de um campo feminista e antiproibicionista vem organizando politicamente as mulheres vítimas da guerra às drogas.

\section{FUN IN GAMES}

Erving Goffman e Robert McGinnis publicaram em 1961, um livro com dois estudos intitulado Encounters: two studies in the sociology of interaction. $\mathrm{O}$ trabalho que particularmente nos interessa nessa obra é Fun in games. $\mathrm{O}$ paper versa sobre quão longe alguém pode ir por tratar a diversão seriamente. 
Como supracitado, não obstante as brincadeiras de Paraná, o jogo é "pegado". 2 Para estes autores, os jogos são um tipo específico de encontro focado; envolvem um foco visual e cognitivo único de atenção. Enquanto estão na quadra, Paraná e demais jogadores encontram-se imersos em um ambiente capaz de intensificar a relevância mútua de seus atos, assim como de maximizar a oportunidade de cada participante perceber o monitoramento do outro sobre ele. "Jadiel, pipoqueiro!", grita um jogador irritado com certo tipo característico de comportamento em campo, marcado pela perceptível falta de comprometimento em participar ativamente das jogadas mais duras. "O cara tá cobrando lateral com a bola rolando", protesta certo jogador ao ver outro, da equipe adversária, desrespeitar uma regra básica do futebol de salão. "Não pode sair assim", do professor a um jogador que abandona o treino em andamento.

Esse monitoramento promove uma abertura mútua à comunicação e possibilita a emergência de um "nós racional" (GOFFMAN e MCGINNIS, 1961, p. 18) como um senso de coisa única que "nós" estamos fazendo naquele momento. Além disto, tanto quanto esses encontros focados consigam prover a base de comunicação para um fluxo circular de sentimentos entre os participantes, conseguirão dispor a eles compensações corretivas para atos desviantes. "Cada um no seu, cada um no seu. Tem dois caras sobrando aqui (sem marcação)", diz um jogador ao time.

Vamos falar um pouco de Maradona, um acolhido ${ }^{3}$ e participante da oficina de futebol, também ex-jogador profissional de pequenas equipes da região de Sorocaba, cidade próxima a capital paulista. Ele chegou a jogar com o jovem atleta profissional de fama internacional, Robinho, antes de este se tornar craque da equipe do Santos F.C. Maradona, certo treino, apresentou-se "cheiradaço", nas palavras do professor e logo ao iniciar a primeira partida daquela tarde, ele lhe chama à atenção. Assim, Maradona permanecerá recebendo comentários sobre seu estado e de como está prejudicando sua equipe até o fim da segunda partida e também coincidentemente ou não, de sua segunda derrota. "Deixou seu time na mão, hein, Maradona", brada o professor após levantar a camisa dele e comentar sua magreza, mesmo tendo o jogador convertido um gol de pênalti. Sobre o comportamento da equipe com Maradona, o professor observa: "Os caras mesmo cobram dele". Coincidentemente, naquele exato momento, ao lado da quadra, Maradona realmente era chamado à atenção. Goffman e McGinnes (1961) devotam especial atenção aos adictos, ou usuários de álcool e drogas e sua possível dificuldade em manejar seu estado de modo discreto quando sob efeito destas substâncias, sem contagiar as obrigações de interação para que o encontro focado, como é o caso da partida esportiva, possa manter sua fronteira.

Voltemos a Paraná, o ex-pai de rua, veremos agora como certas propriedades dos participantes, como ser ex-pai de rua, serão tratadas pelas regras de irrelevância como se não estivessem presentes. Uma atividade engajadora como é o jogo de futebol em geral e particularmente entre nossos interlocutores é capaz de agir como uma fronteira em torno dos participantes, vedando-os dos muitos mundos potenciais de significado e ação. Sem essa barricada abrangente, presumivelmente, os participantes estariam imobilizados por uma inundação de bases para a ação. Em um encontro focado, como são os jogos de futebol, as regras de irrelevância nos falam sobre aquilo a ser ignorado e por consequência o que deve ser tratado como real. Elas tornam possíveis uma matriz de acontecimentos relevantes, ou eventos ligados ao jogo, envolvidos em um esquema de expressão e interpretação, assim como possibilita papéis e identidades geradas pelo jogo. Dessa maneira, Maradona não poderia invocar sua condição de ex-jogador para ser escalado em um campeonato, sua antiga condição e qualquer importância dada a ela é irrelevante frente ao mau desempenho em campo. 
Mesmo o professor é cobrado de acordo com o papel exercido na partida e caso esteja como juiz ou treinador poderá ser questionado ou chamado à atenção. Maradona, ao constatar a segunda derrota de seu time acusa o juiz/ professor de ter "roubado". Em outra oportunidade, ao comentar a escalação para um campeonato no qual participaram equipes de acolhidos, de conviventes e de orientadores socioeducativos, Maradona questiona os critérios adotados na montagem das equipes: "Na cabeça dele de técnico, ele pensou que iria fazer o nome com o outro time e deixou nós [sic] sem reserva". Ainda em outra circunstância ao conversar distraidamente comigo, o professor é advertido por um jogador em campo, de estar demasiadamente absorto pela nossa conversa e não com o desenrolar dos acontecimentos da partida. Ele recebe o aviso: "Você não está vendo o jogo, não?". O juiz, como nos apresentam Goffman e McGinnes (1961) certamente é um recurso percebido, ele faz parte dos eventos e papéis percebidos localmente, como também são os papéis de técnico e jogador.

Paraná, quando não está jogando futebol de salão é pai de rua, mas dentro de quadra é um jogador alegre dado a enfeitar suas jogadas. Depois de desperdiçar algumas oportunidades, seu gol é especialmente comemorado pelos colegas. Em outra ocasião, ao término de uma série de partidas/treino, ele chega a declarar com uma "alegria insopitável e gratuita" (RODRIGUES, 1994, p. 80) que: "Hoje foi bom demais. Nós viemos pra brincar". O jogo permite a expressão de uma faceta jocosa, por certas vezes ele não ser tão "pegado" assim. ${ }^{4} \mathrm{Na}$ ocasião da frase acima, dita por Paraná, os gols sequer foram contados. Além disto, por não ser o jogo semelhante à rua, as regras de irrelevância não permitem às maneiras de pai de rua furar a barreira e adentrar na quadra. Possivelmente por esta razão, Paraná seja considerado o jogador exemplo pelo professor. Antes de começar a jogar futebol, "criava problema e arranjava briga no albergue". As regras de irrelevância obrigaram, ou criaram a possibilidade para que, no jogo, o ex-pai de rua transmutado em jogador demonstre, sob o monitoramento e sanção da equipe, apenas seus atributos ligados à diversão, ou ao bom desempenho do time. Os modos de pai de rua não ajudam a marcar gols e o jogo de futebol compreende uma gama de situações difíceis que cada jogador estará sob risco de encarar. Também demanda as qualidades de mente e corpo que ele precisará para enfrentar bem estas situações. Por isto, é apenas no futebol, por exemplo, que "o zagueiro tem que ter o tempo da bola" (CAVALCANTE, 2011, p. 98), estas qualidades chegam a estar descritas nos manuais de educação física (BOSARI, 1989). Desta maneira, o jogo de futebol parece encaixar-se na conceituação feita por Goffman e McGinnes (1961) sobre encontros focados como algo destacado da vida ordinária.

Percebemos então, como o futebol consegue gerar um mundo diferente do mundo da rua e do uso do crack, mesmo tendo jogadores daí advindos. Seus "movimentos corporais performados localmente" (GOFFMAN; MCGINNES, 1961, p. 28) são enquadrados pelo jogo e caso não sejam apropriados são descartados da realidade pelas regras de irrelevância, quase como uma corporalidade enquadrada. Poderíamos, assim, pensar que a performance no jogo difere da performance vivida nas ruas, e isso gera 'desidentificações' importantes que se refletem nos papeis que cada sujeito assume em cenas de vivências distintas.

Os jogos nos separam da vida ordinária e nos imergem em mais uma de suas possibilidades, eles nos dão a chance de vivermos outras realidades nas quais eventos visíveis irrelevantes serão ignorados; assuntos privados irrelevantes serão mantidos fora da mente e uma inconsciência sem esforço poderá se apoderar de nós (GOFFMAN e MCGINNES, 1961). A perspectiva de jogo reduz a situação a times, um lado do qual passamos a ser o jogador, um agente do jogo que age e faz, não para uma individualidade, mas para uma equipe com quem se compartilha uma identidade de interesse. A atividade básica de um jogo 
é o movimento, cada um selecionado entre limitado número de possibilidades e sendo largamente determinado pelo movimento prévio do time oponente. $\mathrm{O}$ conceito de interação é assim transformado, para Goffman e McGinnes (1961) refere-se agora a uma forma altamente estruturada de destino mútuo.

Este destino mútuo pode ser percebido nas orientações e admoestações do professor referindo-se a comportamentos pouco producentes em campo, mas aparentemente, além disto, inadequados a um ambiente quase familiar: "Vamos parar de xingar aí e jogar mais futebol". Ou, ao ter de dar socorro a um jogador objeto de uma falta mais dura: "Devagar aí, tamo [sic] em família".

O envolvimento completo produzido pelo jogo, apesar de sua trivialidade, pode transformar qualquer participante em um antagonista digno, malgrado grandes diferenças de status social e das possíveis reivindicações de prestígio advindas de outras realidades sociais (GOFFMAN; MCGINNES, 1961). A história do futebol no Brasil é a própria confirmação dessa idéia. No início do século XX, o futebol se tropicalizava no Rio de Janeiro e em São Paulo, deixava de ser privilégio de jovens abastados e satisfeitos em copiar o estilo inglês de jogar para ser "fecundado pela energia criadora do povo que o descobria" (GALEANO, 1995, p. 39). Os usuários de crack também encontraram no futebol e na disputa de campeonatos, oportunidade de, uniformizados e com o desempenho enquadrado pelo jogo, serem reconhecidos socialmente.

O envolvimento é uma possibilidade aberta pelo jogo.O monitoramento mútuo objetiva impedir o livre desenvolvimento da jogada pelo adversário e promover o jogo realizado pela própria equipe. Faz deste envolvimento, uma obrigação a ser sustentada em dada medida; nem exageradamente, nem pouco. Ademais, esse envolvimento espontâneo compartilhado em uma atividade mútua coloca os parceiros em algum tipo de solidariedade exclusiva e permite a eles expressar companheirismo, proximidade psíquica e respeito mútuo; a falha em participar de boa vontade pode ser interpretada como expressão de rejeição aos presentes ou ao contexto (GOFFMAN; MCGINNES, 1961). Não seriam então, sem motivo as declarações de um usuário de crack sobre sua antiga equipe do albergue: "O time faz a gente gostar mais um do outro. Quando alguém fazia dívida, a gente ia lá e pagava. Eu não usava drogas naquela época e sobrava um dinheirinho com que eu comprava refrigerante pra todo mundo [...] um aprende a respeitar mais o outro". Enfim, é o envolvimento de outras pessoas, apesar do possível vazio de interesse de alguém, o fiador da absorção.

\section{OS PÓS-JOGOS}

Ao término das partidas em um treino, o enquadramento relaxa progressivamente e os temas referentes aos jogos vão lentamente arrefecendo e abrindo espaço para outros assuntos. O corpo se encontra em outro estado, após uma série de jogos. A absorção pelo futebol afastou a rotina e estabeleceu seu próprio espaço e tempo. O pós-jogo é momento de relaxamento muscular. Quando em um treino rotineiro, os jogadores se deixam prostrar no chão e podem dividir um cigarro, ou mesmo um baseado, mas também se espera do professor uma espécie de prêmio pelo esforço do grupo em forma de garrafas de refrigerantes e pacotes de bolachas. Enquanto os jogadores estão sentados no chão bebendo e comendo, invariavelmente ele pergunta: "Alguém precisa de alguma coisa?". O sucesso da oficina de futebol em enviar e acompanhar usuários de crack a cursos e novos empregos ${ }^{5}$ está intimamente vinculado ao pós-jogo. 
Os jogadores geralmente são recrutados, como se diz no jargão de Recursos Humanos, na Tenda e levados até o local do treino, além disto, o professor passa pela Cracolândia quase diariamente e quase sempre encontra algum de seus jogadores e ex-jogadores por lá. É a oportunidade de insistir na volta às oficinas de futebol e lembrar algum "corre" a ser feito em prol do usuário, como buscar seus documentos, matricular em algum curso, entrevista de emprego ou conseguir vaga em albergue e, é claro, lembrar a data do próximo treino. Não existe falta de vagas nos cursos e o mercado de trabalho paulistano, em 2014, absorvia todos os encaminhados; a diferença está no salário e tipo de emprego. Para serviços operacionais menos remunerados, com proventos beirando o salário mínimo paulista, há vagas para todos os alfabetizados. Empregos mais complexos como mecânico, por exemplo, um curso como os oferecidos pelo Pronatec se faz necessário. Isto não significa, de modo algum, que não existam dificuldades, como, por exemplo, superar os sentimentos de vergonha advindos da carência, vivida por muitos alunos, de vestimenta apropriada para se apresentar em sala de aula. ${ }^{7}$ Será no pós-jogo que o professor irá se informar sobre essas demandas. Pode acontecer também de alguém que "bateu a nave"expressão usada para recaída no uso - e faltou a algumas aulas precisar ser demovido da ideia de abandonar o curso, ou emprego.

Nesse último caso, os problemas se revelam maiores, dado o despreparo dos departamentos de recursos humanos das empresas demandantes de mão de obra das Tendas em lidar com funcionários usuários de drogas. Como é muito usual "bater a nave" ao receber o primeiro salário, os funcionários são demitidos dentro do período de experiência no emprego, retornando à condição de desempregados, porém, em piores condições devido ao fracasso laboral.

Estes assuntos são tratados com cuidado pelo professor e ele tem essa possibilidade pela proximidade cotidiana e vínculo pessoal estabelecido através das oficinas de futebol. Muitas vezes, o processo se inicia na decisão do participante em retirar seus documentos. A resposta é imediata. De posse de um telefone celular com câmera, o professor procura a primeira parede branca e tira a foto necessária à confecção da carteira de identidade. Caso isso fosse feito na Tenda, demoraria dias ou semanas até se disporem a executar o gasto da foto e revelação. A resposta imediata se mostra fundamental e parte disto é custeada pelo professor e a outra pela Tenda. O trabalho é por ele executado fora do horário das oficinas, isto é possível graças a um contrato laboral que lhe dispõe certo número de horas remuneradas para este tipo de atividade. Este comprometimento pode estar ligado ao fato dele ser ex-usuário de crack na região, ex-acolhido e ex-convivente.

As oficinas de futebol possuem data fixa, no entanto, o professor tem contato com os jogadores durante ao menos, 4 dos 5 dias úteis e nos finais de semana com campeonato ou outras atividades. Por outras atividades chamamos os passeios com treino em locais comumente não frequentados pelos jogadores, como as quadras do Parque do Ibirapuera e visitas a estádios de futebol, por exemplo. Estes contatos se dão na Tenda, na Cracolândia e nas ruas do Bairro da Barra Funda e Bom Retiro, principalmente. O processo de recrutamento de novos participantes acontece nestes locais e é por convite informal. Não é necessário nenhum tipo de inscrição ou compromisso com a assiduidade na oficina. Apenas em caso de campeonatos, os jogadores que poderão entrar em campo serão os presentes nos treinos específicos para a disputa.

Os participantes não são obrigados a cessar o uso de drogas antes dos treinos. Houve um caso interessante de atraso no transporte da Tenda para a quadra e os "meninos" permaneceram por algumas horas cheirando solvente Thinner até a chegada do transporte. ${ }^{8}$ 
Após se saber quem são os jogadores daquela tarde, todos passam a aguardar o transporte do lado de fora da Tenda. A agitação costumava ser grande, havia muita ansiedade para jogar bola. $\mathrm{O}$ uniforme esportivo, camisas do time e chuteiras são trazidos de casa, geralmente a pé, pelo professor após ele mesmo os ter lavado. Todos na Kombi, saem em velocidade acelerada ao som invariável de músicas de rap com temática baseada na vida de rua, consumo de crack e problemas com a polícia como a música Mágico de $\mathrm{Oz}$ do grupo Racionais MC. ${ }^{9} \mathrm{O}$ volume é alto, as curvas são feitas com muita velocidade, principalmente por se tratar de uma Kombi, e a conversa flui quase aos gritos. No retorno, após o jogo, a mesma rotina excetuando a parada para consumo de refrigerantes e bolachas.

Geralmente, o pós-jogo consiste da devolução dos uniformes e troca de roupa, saída para a rua e entrada na Kombi com música de temática próxima à realidade fora das quadras, em alto volume. Em seguida, uma parada para $\mathrm{o}$ professor comprar refrigerantes e biscoitos, às vezes são fornecidos pela Tenda, mas é raro. O professor retorna ao transporte até nova parada nas proximidades do destino. Todos descem, sentam em sua maioria no chão e se inicia a distribuição dos copos, garrafas e sacos com biscoitos. Caso alguém deixe copos pelo chão, geralmente os participantes sob maior efeito de álcool, (o professor reconhece nunca ter tido problema com uso de crack, só com excesso de álcool) será chamado à atenção, muitas vezes sem sucesso. Finalmente, enquanto todos relaxam sentados, consumindo refrigerantes e bolachas, o professor pode fazer sua pergunta dedicada a iniciar ou dar continuidade ao atendimento de demandas: "Alguém precisa de alguma coisa?".

\section{AUTOCONTROLE, O USO DE CRACK E OFICINAS DE FUTEBOL}

Nos jogos de futebol entre usuários de crack, álcool e outras drogas, o abuso destas, antes de uma partida, é a acusação padrão para um mau desempenho. Caso o time saiba de algum jogador que tivesse feito o uso de drogas na noite anterior a uma partida, ou tenha "batido a nave", este jogador será seguramente o bode expiatório, principalmente em caso de derrota. Possivelmente, sua má atuação pode até ser menos devida ao seu uso de substâncias psicoativas, ou a uma noite não dormida do que à pressão do grupo condenando seu comportamento. O jogador assíduo aos treinos e cumpridor do resguardo de drogas na véspera, não será reprimido pelas mesmas críticas feitas ao jogador displicente. Cheguei a presenciar acusações enérgicas após uma derrota em um campeonato, contra um jogador: "Não vem treinar é isso, é isso. É isso que dá não vir treinar."

Vimos como o envolvimento espontâneo compartilhado em uma atividade mútua coloca os parceiros em algum tipo de solidariedade exclusiva e permite a eles expressar companheirismo, proximidade psíquica e respeito mútuo. A falha em participar de boa vontade pode, em consequência, expressar rejeição aos presentes ou ao contexto. Isso nos remete à maneira como os encontros focados conseguem prover a base de comunicação para o fluxo de sentimentos entre os participantes e proporcionar a eles compensações corretivas para atos desviantes (GOFFMAN; MCGINNES, 1961). Certa feita, as acusações sobre uso de drogas foram feitas durante todos os momentos difíceis da partida. A cada insucesso, elas retornavam mais fortes, minando visivelmente a autoconfiança do acusado e acirrando ainda mais os ânimos dos outros jogadores contra ele. $\mathrm{O}$ mau desempenho parecia confirmar as expectativas dos demais jogadores sobre como o consumo de drogas prejudica a atuação em 
campo, contribuindo para reforçar ainda mais as críticas sobre ele. A própria relação tática se modificava, e o jogador acusado era agora um desqualificado (GOFFMAN, 1975) dentro de campo, pouco merecedor de receber passes dos demais e assim, diminuindo as chances de ter sua atuação reconhecida pela execução de boas jogadas e marcação de gols. Se para Whyte (2005), em seu clássico estudo sobre os garotos italianos imigrantes nos EUA do começo do século XX, existe uma correspondência entre a posição da pessoa no grupo, fora das quadras de boliche, e o desempenho dentro delas proporcionado pela pressão do grupo. Pudemos observar uma simetria entre o resguardo de drogas antes das partidas e o desempenho dentro de quadra, porém esse desempenho nos pareceu tão fortemente influenciado pela pressão da equipe de jogadores, quanto o foi na descrição e análise de Whyte.

Goffman e McGinnes (1961) mencionam a descrição da "pura sociabilidade" feita por Simmel, para situar o advento moderno da universalidade das regras: "Riqueza, posição social, erudição, fama, capacidades excepcionais e méritos, não devem tomar nenhuma parte na sociabilidade" (SIMMEL, 1950, p. 45-46). Também dizem respeito às regras, as considerações weberianas sobre o capitalismo e seu modo de transcorrer "sem considerar as pessoas", o lema do mercado, assim como, na moderna burocracia, o primado da "igualdade perante a lei" (WEBER, 1946, p. 215-216). Ou, no caso do futebol, perante a regra.

Essas ideias a respeito da universalidade das regras presentes no futebol são mencionadas por Roberto DaMatta ao procurar traçar um paralelo entre o "corpo universal" (DAMATTA, 2006) da modernidade e, recorrendo a Gilberto Freyre, os corpos tradicionais de senhores e escravos, estes, ativos e fortes, enquanto aqueles seriam sedentários. O futebol traria a ideia de um corpo desejado por todos, independentemente de posição social. Segundo este autor, a sociedade brasileira na época da chegada do futebol no país, na virada do século XIX para o século XX, discutia a ideologia liberal da meritocracia e o futebol seria um esporte meritocrático, por meio do qual um corpo talentoso e capaz de alto desempenho nos campos seria capaz de proporcionar mobilidade social a alguém. Parece que o autor prefere não levar em conta o fato de o futebol ter sido profissionalizado no país, apenas em meados dos anos 1930, nem de o destino dos jogadores oriundos da classe trabalhadora, mesmo para aqueles com sucesso dentro de campo, fosse retornar à miséria de onde vieram e, não poucas vezes, em condições ainda piores que seus pares trabalhadores e isto, até poucas décadas atrás. Mesmo assim, futebol teria sido nosso "mais contundente professor de democracia e igualdade" (DAMATTA, 2006, p. 142) por afirmar os valores capitalistas básicos. Ainda segundo esse autor, o individualismo e o igualitarismo presentes na prática futebolística, também viriam ao auxílio da "socialização de uma justiça burguesa e universalista" (DAMATTA, 2006, p. 150). O individualismo estaria contido na possibilidade, entre outras, de todos poderem se tornar atletas, embora, esqueça o autor o fato dos jogadores profissionais estarem desde os primórdios do profissionalismo, presos aos clubes como os servos à terra (GALEANO,1995) por contratos vitalícios, apenas podendo eles, se deslocarem de equipe, com a anuência do time dono de seu passe. O próprio Roberto DaMatta reconhece a dificuldade dos imperativos liberais descerem à terra e afirma que "a regra impessoal e igualitária opera até o ponto de não ameaçar os privilégios como outras sociedades com forte ranço tradicional, (com destaque nas relações pessoais, verticalizadas e hierárquicas)" (DAMATTA, 1982, p. 35).

Seria talvez mais cuidadoso se ficássemos com as ideias de Richard Sennet sobre a relação entre regras e igualdade nos esportes: "Jogar requer uma libertação de si mesmo, mas essa liberdade só pode ser criada por meio de regras que estabelecerão uma ficção de igualdade inicial de poder entre os 
jogadores" (SENNET,1988, p. 389, grifo nosso). Se olharmos mais atentamente, dentro de campo, nenhum jogador é igual ao outro. Seja em habilidade, em posicionamento, ou em temperamento. Sejam nas suas obrigações decorrentes da posição. Um ala não tem a mesma obrigação de defender o time dos ataques alheios que um pivô, mais sujeito a cometer faltas e ser penalizado ou vitimado pelas regras. $\mathrm{O}$ juiz, certamente entra em campo com um conceito a respeito dos jogadores com quem lidará durante a partida. Um imperativo de igualdade quando desce das alturas da ideologia, aparentemente serve mais à instauração da desigualdade e menos a propósitos igualitários.

Os jogos populares de futebol em Salvador, brilhantemente descritos e analisados por Jeferson Bacelar (1991) promovem dois movimentos complementares, primeiro uma inversão da ordem estabelecida pela vitória dos times de jogadores proletarizados sobre os de classe média; e em segundo lugar, um "reforço da coesão coletiva e no exclusivismo grupal" (BACELAR, 1991, p. 110). Estes trabalhadores acostumados às derrotas diárias, têm no "baba" a possibilidade da vitória e da realização pessoal. O prestígio como jogador está não só associado ao desempenho, mas a uma performance de valentia e ao seu passado no bairro. Como não há juiz, o prestígio possibilita a manipulação das regras e influência nos resultados e estes voltam a confirmar a importância da pessoa por uma espécie de retroalimentação. A liderança "não se faz apenas no 'baba' em si, refletindo também o estatuto dos jogadores no bairro e suas relações com a sociedade mais ampla" (BACELAR, 1991, p. 98). Assim, o "baba" permite a passagem através da barreira em torno do jogo, de alguns privilégios e do prestígio auferido externamente. As regras de irrelevância não se aplicam a valentia provada em embates pelo bairro. Como não há técnico, são os líderes os responsáveis por montar e instruir os times; na ausência de juiz, manipulam as regras e sua capacidade de manipulação se encontra ligada a seu estatuto no bairro. Ainda assim, como as regras podem ser manipuladas, mas não modificadas, times de jogadores anônimos conseguem, por vezes, vencer equipes de líderes do bairro.

Ao observar um "baba" jogado em Salvador, Jeferson Bacelar relata um incidente em que uma liderança também usa o consumo de maconha como motivo de acusação, ao discutir o desempenho de um jogador durante uma partida: "É melhor você ficar calado, fumando suas 'coisas' prá eu não lhe dar uns murros" (BACELAR, 1991, p. 100). Semelhante acusação está presente na etnografia de Villela (1997) sobre uma "pelada" fluminense, quanto ao uso de maconha e cocaína, porém, o uso da primeira pôde também ser associado ao bom desempenho em campo. O uso de "brizola" como era chamado o "pó" na época da pesquisa, é motivo para as "zombarias mais pesadas", em tom moralista de acusação sobre seu uso continuado. A maconha, no caso de melhora incomum na atuação em uma partida, ou mesmo em uma jogada é, como dissemos acima, positivamente agregada a esse sucesso: "essa é da boa!" (VILLELA, 1997, p. 73).

O jogo instala um enquadramento através de regras de irrelevância e transformação capazes de estabelecer uma barreira permeável com o mundo externo. Este enquadramento permite a absorção dos participantes, jogadores ou torcedores nos eventos da partida. Agora, devemos nos perguntar no que consiste esta absorção. Quais são as suas características e como agem na interação dentro da partida. Podemos ver a atuação de um time como uma orquestração, na qual cada ação deve ser harmônica com as outras, com jogadores se comunicando em busca da vitória comum. A comunicação corporal durante uma partida de futebol depende da posse ou não da bola; o possuidor intenciona vencer a marcação do adversário, enquanto este age no sentido de quebrar a interação adversária e tomar posse da bola pela marcação. Com ela se busca 
isolar, impedir a comunicação e induzir a uma arriscada jogada individual, colocando frente a frente marcador e driblador. Um procura limitar espaços; enquanto outro, pela ambiguidade dos movimentos do drible, tenta burlar o adversário (CAVALCANTE, 2011).

O futebol se massifica no Brasil, a partir dos campos das elites e da intromissão dos gandulas pobres e de jogadores proletários utilizados na ausência de número suficiente de jovens ricos dispostos a jogar. Essa primeira fase de futebol popular, após seu início elitista, pode ser entendida como o tempo do império da malandragem (CAVALCANTE, 2011). Assim, um habitus malandro baseado na valoração da diversão, experimentação e sedução surge diferente do futebol das elites, ele é marcado por um baixo autocontrole das paixões por parte dos gandulas e vadios a observar os jogos. Enquanto o futebol de elite era caracterizado pelo modelo inglês com chutes para frente e muita correria, o malandro se diferenciava por estar imerso em um contexto periférico das cidades com frouxas redes de interdependência, pressuposto para certa irresponsabilidade e abrindo caminho para a busca da satisfação e experiência corporal. Em contextos sociais diferentes, os modelos de autocontrole também se afastam.

A várzea é o lugar do vadio, do gandula, do malandro e de uma rede de sociabilidade aberta para a criatividade; nela, o malandro está à procura de diversão. Seu potencial inventivo está materializado no drible, no chute "folha seca" e no "chute bicicleta". Na atualidade, o futebol amador na cidade de São Paulo ainda é conhecido como futebol de várzea. A região da Barra Funda e Bom Retiro, onde jogam nossos usuários de crack, é a mesma do nascimento de inúmeros clubes de várzea. A rua, assim como a várzea, é lugar de experimentação e criatividade constantes entre moradores das calçadas, baixos de viadutos e os mais diversos tipos de "mocós". ${ }^{10}$

Não nos parece coincidência ter o jogo de futebol feito tanto sucesso entre os usuários de crack e também parte da população de rua. A quadra ou campo e a rua estão abertos à experimentação, criatividade e busca por diversão. Porém, não apenas de malandragem e diversão é feito o futebol praticado nas Tendas. Aí, também há uma "contaminação disciplinar" (CAVALCANTE, 2011, p. 23). O futebol com disciplina, no sentido de melhorar a eficiência do jogador e da equipe em jogos de projeção midiática, pelo adestramento do corpo e ordenamento do espaço com atenção para a distribuição dos jogadores em campo, seu posicionamento e ajustamento para máximo rendimento dos movimentos e gestos por meio de atividades codificadas em táticas (FOUCAULT, 1997). Acabou por transformar o lugar da experiência, marca do futebol malandro, no da tática, como expresso na frase: "Vamos fazer o que o professor pediu para sairmos com a vitória!" (CAVALCANTE, 2011, p. 30). A tática visa criar conectividade entre os espaços individuais incorporados a cada jogador pelo treinamento de suas características físicas, técnicas, táticas e psicológicas. Enfim, uma nova consciência para tomada de decisões corretas, identificação de problemas e seleção de habilidades para resolvê-los, ao mesmo tempo em que se cria e nega espaços (NETO; LEITE, 2010). A consciência desta interdependência gerada pela divisão de funções na quadra suscita o rebaixamento moral da diversão, deixada de lado em nome da equipe interdependente, por dispositivos incorporados para maior autocontrole dos impulsos. Soma-se a isto, o fato de que a medida em que a oficina de futebol passa a ser um treino destinado à participação em campeonatos e, posteriormente, ao campeonato propriamente dito, passa-se de situações sem autoridade central, sem juiz, contando apenas com algumas intervenções do professor, para a monopolização da organização das equipes pelo professor/técnico e pelo também monopólio das decisões quanto à interpretação das regras, concentrado no juiz. 
Para além da coerção social, o autocontrole seria uma transformação da economia psíquica pela interiorização das proibições, no sentido de se refrearem os impulsos espontâneos e movimentos imediatos. Segundo Elias, novas relações sociais são capazes de suscitar mudanças nos controles dos impulsos e das paixões no decorrer de transformações específicas nas inter-relações humanas (ELIAS; KAMNITZER, 2007). O jogo impõe normas e valores cujos preceitos são obrigatórios para os indivíduos, a não ser pela desistência em participar da equipe, mas como vimos acima, os jogadores que observamos querem jogar e vencer. A racionalidade do jogo se impõe paralelamente a determinadas coerções no sentido do autocontrole das emoções e movimentos.

Em um campeonato "de rua", realizado no ano seguinte ao Intertendas, a equipe adversária proveniente de outra Tenda conhecida como Complexo Prates teve um jogador reserva expulso nos instantes iniciais da partida por perguntar ao juiz se ele estaria "chupando o apito" ao não marcar uma pretensa falta em favor de seu time. Enquanto isso, pela outra equipe, o professor advertia para ninguém desrespeitar o juiz. Porém, essa recomendação foi feita mais devido a terem testemunhado a expulsão e menos pela real disposição dos jogadores de sua equipe em ofender o juiz. Como se a coerção externa tivesse sido apropriadamente transformada em coerção interna, em uma racionalidade entendida como modelo conceitual duradouro "da realidade observável nos comportamentos individuais" (ELIAS, 2001, p. 120).Um jogador expulso prejudica seu time, posteriormente a expulsão descrita acima, outro jogador da mesma equipe seria expulso por cometer falta grave e seu time terminou a partida com uma derrota por cinco gols a dois. É toda uma rígida rede de interdependência a exigir um autocontrole rigoroso como meio de evitar a ação impulsiva. Esta seguiria a pressão das emoções externas ao jogador, mas internas ao jogo levando a equipe ao fracasso. $\mathrm{O}$ jogo de futebol é um enfrentamento entre equipes submetidas à mesma regra e com um juiz responsável por interpretá-la a cada jogada e distribuir as punições. Nele, a luta aberta entre jogadores está fora das possibilidades permitidas pelas regras adotadas, e tanto quanto existe uma barreira a enquadrar o jogo e a defendê-lo das influências externas, irá se desenvolver através dos treinos e jogos em campeonatos, uma couraça protetora no jogador contra o extravasamento de certas emoções. Essa couraça mantém as emoções sem vazão para o mundo externo e também retém este mundo fora do sujeito. Assim, abre a possibilidade da elevação de "um muro real interpondo-se entre eles mesmos e os objetos de sua reflexão" (ELIAS, 2001, p. 279). O futebol abre espaço momentâneo para se separar do mundo e o autocontrole do jogador inserido na tática da equipe ajuda no soerguimento da couraça necessária à reflexão sobre a realidade externa.

Para compreendermos a extensão das consequências desse envolvimento no jogo, faz-se necessário revisitar um importante conceito para compreender as flutuações no consumo de drogas, o de estrutura de vida (GRUND, 1993). Ela se refere a padrões regulares de atividades laborais, recreativos, domésticos e criminais que moldam e constrangem o dia a dia de usuários. São essas atividades regulares (tanto convencionais quanto as relacionadas ao uso de drogas) que estruturam os padrões diários como determinantes chaves da estrutura de vida. Parece lógico incluir os relacionamentos pessoais, compromissos, obrigações, responsabilidades, metas e expectativas. Relacionamentos 242 que são exigentes e simultaneamente tem valor social (afetos) ou econômico (salários) são determinantes igualmente importantes para a estrutura de vida. Contatos regulares com usuários controlados e não usuários são, também de considerável importância, assim como a participação nas estruturas e atividades não motivadas (primariamente) por incentivos relacionados a drogas. 
A importância da estrutura de vida é muito claramente demonstrada pela sua ausência, como representado pelo que Grund (1993) chama de junkie de rua. Esse tipo de usuário se assemelha com a quase totalidade dos participantes da oficina de futebol, a condição de viver do "corre" incerto e diário, sem uma renda fixa assegurada. Assim como o junk de rua, o usuário de crack sujeito a uma mudança repentina na disponibilidade de drogas - mesmo que seja no sentido de torná-la mais abundante - vê perturbado ou desestabilizado seu padrão diário e estabelecido de atividades (tanto convencionais como relacionado a drogas) e pode levar a uma escalada do uso.

No estudo de Grund (1993) sobre usuários de heroína, foi constatado o fato de um traficante bem-sucedido se vir obrigado a trabalhar sempre em horas fixas, com um time razoável de empregados e manter um registro preciso do balanço financeiro. Devido a isso, não pode, por exemplo, aparecer no ponto de venda em horas irregulares, pois esse comércio varejista para ser bem-sucedido requer estabilidade e continuidade. Tais estipulações estruturam substancialmente a alocação de tempo dos traficantes de sucesso. Assim, a forma e o grau de estrutura de vida são resultado de atividades regulares, relacionamentos, compromissos, responsabilidades e ambições que podem estar ligados ou não às drogas.

A participação nas oficinas de futebol pode ser vista em um contínuo de estrutura de vida, partindo da entrada na oficina e frequência esporádica nos treinos, culminando nas atuações em campeonatos "de rua" com treinos circunscritos à equipe. Nesse trajeto, o jogador passa de frequentador ocasional a assíduo nos treinos, comprometendo-se com datas e horários e também passa a estar disponível em horários e dias fixos na Tenda para seguir ao treino na Kombi. Posteriormente, pode ingressar em equipe participante de "campeonato de Tenda", juntamente com os jogadores ligados aos equipamentos públicos dedicados à população em situação de rua; depois, em campeonatos externos e ter contato com equipes fora deste universo. Paralelamente, segue a tirada de documentos, matrícula em cursos e admissão em um emprego remunerado com carteira assinada. A saída da rua iniciada pelo frequentar da Tenda prossegue com a ida para um centro de acolhida, ou albergue e posteriormente a um Hotel Social $^{11}$ e repúblicas ${ }^{12}$, até um possível reencontro familiar. Em paralelo, vem o maior autocontrole no uso de álcool e drogas, particularmente o crack e a inserção no mercado de trabalho.

\section{DE BRIGAS DE GALOS E INCIDENTES ENTRE HOMENS}

As regras de irrelevância são fundamentais para tornar possível um encontro focado com as características do jogo de futebol, particularmente quando jogado por homens dispostos em hierarquias formalmente estruturadas dentro de equipamentos públicos destinados ao atendimento da população em situação de rua. A inobservância dessas regras pode provocar incidentes capazes de desobrigar os participantes a sustentar seu disfarce e a própria interação face a face enquadrada. As "rivalidades do status" (GEERTZ, 1989, p. 291) celebradas na famosa descrição sobre a briga de galos em Bali, não parecem estar disponíveis à celebração nos jogos absorventes entre homens.

Uma briga de galos absorvente, termo que Geertz tira de Fun in Games, é aquela na qual se defrontam "os mais iguais e melhores possíveis" (GEERTZ, 1989, p. 298) e, assim como no jogo entre homens, muito pode estar em questão, "o saber, a estima, a honra, a dignidade, o respeito - em suma, o status" (GEERTZ, 1989, p. 300) que pode ser afirmado ou momentaneamente insultado. 
Mesmo porque, no caso balinês as somas apostadas não são suficientes para alterar a hierarquia das fortunas pessoais em longo prazo. A hierarquia moral quando posta em questão torna o jogo mais absorvente, são os jogos no qual o status de alguém influente está sob ameaça, os jogos movidos a dinheiro, que não colocam nenhuma posição social em jogo, são menos absorventes. Porém é pelo dinheiro em vultosas quantias que pode ocorrer "a migração da hierarquia de status balinesa para o corpo da briga de galos" (GEERTZ, 1989, p. 303). Na briga de galos, o prestígio pessoal pode ser reafirmado, celebrado e dramatizado. Os balineses podem brincar com o fogo "sem o risco de se queimar" (GEERTZ, 1989, p. 308) e exibir suas paixões sociais nesta caricatura de guerra, sem alterar a hierarquia. São os sentimentos sobre esta hierarquia que podem revelar-se nas lutas, nesta interpretação balinesa de sua própria experiência.

Os jogos por nós observados no Intertendas e campeonatos "de rua" podem desmoronar caso o status pessoal não seja devidamente contido pelas regras de irrelevância. As brigas de galos em Bali eram desfeitas pela ação da polícia, na Barra Funda, os jogos de futebol podem ruir pela ação dos participantes. Isso nos revela uma diferença entre as disputas entre homens e as disputas entre homens através de não humanos. O enquadramento dos animais não depende de seu disfarce, tão pouco de sua vontade. Para ter uma luta de galos absorvente, os donos dos animais manipulam apostas em animais mais ou menos identificados com homens. Porém os galos não podem deixar de apoiar sua interação na briga e abandoná-la; os homens sim, a aposta destes é neles mesmos.

\section{CONSIDERAÇÕES FINAIS}

Para concluir este artigo, é importante observar que a retomada do emprego na cidade de São Paulo deu início a um processo de proletarização do lumpesinato, nitidamente percebível no dia a dia de quem acompanha os serviços direcionados à população de rua, com os quadros de avisos dos equipamentos públicos como Tendas e Centros de Convivência repletos de papéis anunciando vagas de trabalho. Assim como, pelos panfletos distribuídos pelas assistentes sociais com indicações de locais de contratação imediata de mão de obra e nas conversas com acolhidos, conviventes, orientadores socioeducativos e técnicos. Esse fator socioeconômico é o pano de fundo estrutural, juntamente com a grande disponibilidade de acesso a cursos de formação profissionalizante gratuitos como o Pronatec, para compreender as consequências das oficinas de futebol sobre seus jogadores, na imensa maioria usuários de crack.

O jogo de futebol fornece a possibilidade de grande absorção em seu interior, pelo enquadramento gerado pelas regras de irrelevância. Esse envolvimento profundo permite ao professor trabalhar tecnicamente os jogadores, aumentando sua interdependência, sintonia e orquestração. A vontade de jogar e de vencer leva à participação em campeonatos e a deslocamentos para realidades fora daquelas próprias ao cotidiano da rua. Ao mesmo tempo, no pós-jogo, o professor oferece uma série de serviços e indica outros rumos a serem seguidos pelos jogadores. Mas essas aberturas de perspectiva só logram êxito com o acompanhamento do jogador pelo professor. É necessário, assim, abandonar visões ingênuas do esporte como as expressas no lema: "Esporte não é droga. Pratique". Oriundo de campanhas de prevenção ao abuso de drogas da década de 1980. O futebol em si mesmo pode exercer apenas alguma influência sobre o autocontrole do usuário de drogas sobre seu consumo. Para haver adesão às oficinas, é fundamental, como declarou o professor, trabalhar na perspectiva de redução de danos onde "ninguém precisa parar de usar". Tal mudança no uso só é possível no contexto de um ambiente socioeconômico onde o mercado de 
trabalho se mostra menos excludente, com uma mudança na estrutura de vida do usuário gerada pelos compromissos advindos dos ciclos de treinamentos e jogos, assim como por um acompanhamento individual pelo professor. Sem isso, o esporte pouco poderia influenciar nos padrões de uso.

\section{NOTAS}

${ }^{1}$ Aqui entendida segundo as pesquisas de Grund (1993).

${ }^{2}$ Termo utilizado para designar uma partida muito disputada de futebol.

${ }^{3}$ Termo técnico utilizado pelos orientadores socioeducativos e demais profissionais dos equipamentos destinados a abrigar a população em situação de rua para referir-se a essa população quando atendida. Para aqueles usuários apenas dos serviços da Tenda, o termo utilizado é convivente.

${ }^{4}$ Não é em qualquer ocasião que esta condescendência está presente. Em outro treino com jogos mais "pegados", um jogador que tentou fazer gols com excesso de dribles foi ridicularizado como "Neymar do crack", "Neymar do tráfico" e "Neymar do fluxo".

${ }^{5}$ Um ex-jogador chegou a aparecer na propaganda política do Partido dos Trabalhadores como exemplo de ex-aluno do Pronatec, empregado. Disponível em: http://www. youtube.com/watch?v=L9nJ6EdJaQg. Acesso em: 11 nov. 2014. Foram cerca de 90 jogadores com seus documentos providenciados e 45 enviados a cursos e vagas de empregos. Isto, somente pelo orientador socioeducativo por nós acompanhado nesta pesquisa. ${ }^{6} \mathrm{O}$ termo "corre" geralmente designa o movimento do usuário de crack em busca de fundos, ou seja, "Fazer um corre".

${ }^{7}$ Aqueles em situação de rua têm muitas vezes na Tenda, sua porta de entrada para o sistema de acolhimento. Mas isso não significa, de modo algum, disponibilidade para entrar no prédio de uma universidade e cursar o Pronatec.

${ }^{8} \mathrm{O}$ professor se viu em uma situação delicada pelo atraso da Kombi. Misturado à vontade de jogar, agregava-se a possibilidade de não poder mais usar a quadra devido ao estado dos participantes.

${ }^{9}$ Letra do grupo Racionais Mcs - presença constante nos trajetos entre Tenda e quadra.

${ }^{10}$ Nome dado aos locais utilizados como moradia, por exemplo, buracos embaixo de viadutos.

11 "Esta modalidade é ofertada aos usuários independentes e socialmente ativos através de convênio vinculado com hotéis" (PREFEITURA DE SÃO PAULO, 2009, p. 116).

12 "Unidade de acolhida desenvolvida em sistema de cogestão, com capacidade que varia de acordo com o ciclo de vida, gênero, de forma diferenciada para cada faixa etária e diferentes segmentos, com atenção às demandas e necessidades específicas do público a que se destina.” (PREFEITURA DE SÃO PAULO, 2009, p. 120-121).

\section{REFERÊNCIAS BIBLIOGRÁFICAS}

ALVES, Ygor Diego Delgado. O uso do crack como ele é: o cachimbo, o "bloco" e o usuário. Etnográfica. Revista do Centro em Rede de Investigação em Antropologia, v. 20, n. 3, p. 495-515, 2016.

. Jamais fomos zumbis: contexto social e craqueiros na cidade de São Paulo. Salvador: Edufba: Cetad, 2017. 350p.

ALVES, Ygor Diego Delgado; PEREIRA, Pedro Paulo Gomes. Uma antropologia do "fluxo": reflexões sobre dependência no contexto do crack. Revista

Internacional Interdisciplinar INTERthesis, v. 16, n. 1, p. 121-142, 2019.BACELAR, J. Gingas e nós: o jogo do lazer na Bahia. Salvador: Fundação Casa de Jorge Amado, 1991.

BOSARI, J. R. Futebol de campo. São Paulo: EDU, 1989. 
CAVALCANTE, D. F. Faces do futebol-arte no Brasil: da sedução malandra à imaginação. Fortaleza: Expressão Gráfica, 2011.

DAMATTA, R. Um ensaio sobre o futebol brasileiro. In: DAMATTA, R. Universo do futebol: esporte e sociedade brasileira. Rio de Janeiro: Pinakotheke, 1982.

DAMATTA, R. Antropologia do óbvio: um ensaio em torno do significado social do futebol brasileiro. In: DAMATTA, R. A bola corre mais que os homens: duas copas, treze crônicas e três ensaios sobre futebol. Rio de janeiro: Rocco, p. 201, 2006.

DOMANICO, A. "Craqueiros e Cracados: bem vindo ao mundo dos nóias!" Estudo sobre a implementação de estratégias de redução de danos para usuários de crack nos cinco projetos-piloto do Brasil. 2006. 220f. Tese (Doutorado) Universidade Federal da Bahia, Faculdade de filosofia e Ciências Humanas, Salvador, 2006.

ELIAS, N. A sociedade de corte: investigação sobre a sociologia da realeza e da aristocracia da corte. Rio de Janeiro: Zahar, 2001.

ELIAS, N.; KAMNITZER, P. La dynamique de l'Occident. Paris: pocket, 2007.

FERNANDEZ, O. R. Coca light? Usos do corpo, rituais de consumo e carreiras de "cheiradores" de cocaína em São Paulo. 327f. Tese (Doutorado) - Universidade Federal da Bahia, Faculdade de Filosofia e Ciência Humanas, Salvador, 2007.

FERNANDES, Luís e PINTO, Marta. El espacio como dispositivo de control social: territórios psicotrópicos y politicas de la ciudad. Monografias Humanitas, Fundación Medicina y Humanidades, n. 5, p. 147-162, 2004.

FROMM, Deborah. Percursos e refúgios urbanos. Notas sobre a circulação de usuários de crack pela trama institucional da Cracolândia de São Paulo. Ponto Urbe - Revista do núcleo de antropologia urbana da USP, n. 21, 2017. FOUCAULT, M. Vigiar a punir: história da violência nas prisões. Petrópolis, RJ: Vozes, 1997.

FRÚGOLI JR, Heitor. Roteiro pelo bairro da Luz, São Paulo. Ponto Urbe Revista do núcleo de antropologia urbana da USP, v. 1, n. 1. 2008.

FRÚGOLI JR, Heitor; CAVALCANTI, Mariana. Territorialidades da(s) cracolândia(s) em São Paulo e no Rio de Janeiro, Anuário Antropológico, II, p. 73-97, 2013.

GALEANO, E. Futebol ao sol e à sombra. Porto Alegre: L\&PM, 1995.

GEERTZ, C. Um jogo absorvente: notas sobre a briga de galos balinesa. In: GEERTZ, C. A interpretação das culturas. Rio de Janeiro: Guanabara Koogan, p. 278-321, 1989.

GOFFMAN, E.; MCGINNIS, R. Encounters: two studies in the sociology of interaction. Indianápolis: The Bobbs-Merrill, 1961.

GOMES, Bruno Ramos; ADORNO, Rubens de Camargo Ferreira. Tornar-se "noia": trajetória e sofrimento social nos "usos de crack" no centro de São Paulo. Etnográfica. Revista do Centro em Rede de Investigação em Antropologia, v. 15, n. 3, p. 569-586, 2011.

GRUND, J. P. C. Drug use as a social ritual: functionality, symbolism and determinants of self-regulation. Rotterdam: Institute Voor Verslavingsondersoek, Erasmus Universiteit, 1993.

HUIZINGA, J. Homo Ludens: o jogo como elemento da cultura. São Paulo: Perspectiva, 1996.

MAGNANI, José Guilherme Cantor. “Vai ter música?”: para uma antropologia das festas juninas de surdos na cidade de São Paulo. Ponto Urbe. Revista do núcleo de antropologia urbana da USP, n. 1, 2007. 
MALHEIRO, Luana Silva Bastos. Entre sacizeiro, usuário e patrão: Um estudo etnográfico sobre consumidores de crack no Centro Histórico de Salvador. TAVARES, L. A.; Crack. Contextos, padrões e propósitos de uso. Salvador: Editora UFBA, Centro de Estudos e Terapia do Abuso de Drogas, p. 223-314, 2013.

Tornar-se mulher usuária de crack: trajetória de vida, cultura de uso e políticas sobre drogas no centro de Salvador-BA. 2019. 292f. Dissertação (Mestrado) - Universidade Federal da Bahia, Faculdade de Filosofia e Ciência Humanas, Salvador, 2019.

MEDEIROS, Regina. Construção social das drogas e do crack e as respostas institucionais e terapêuticas instituídas. Saúde e Sociedade, v. 23, p. 105-117, 2014. NASSER, Marina Mattar Soukef. Entre a ameaça e a proteção: categorias, práticas e efeitos de uma política de inclusão na Cracolândia de São Paulo, Horizontes Antropológicos, n. 50, p. 243-270, 2018.NETO, A. M.; LEITE, M. M. Capacidade do jogo e consciência tática: como desenvolver? Disponível em: http://joseaugustolealfutsal.blogspot.com.br/2010/06/artigo-capacidade-do-jogo-e-consciencia.html. Acesso em: 14 fev. 2014.

PELÚCIO, Larissa. Na noite nem todos os gatos são pardos. Cadernos Pagu, v. 25, p. 217-248, 2005.

PREFEITURA DE SÃO PAULO. Secretaria Municipal de Assistência e Desenvolvimento Social. Plano de assistência social do município de São Paulo. São Paulo, 2010.

RAUPP, Luciane; ADORNO, Rubens de CF. Uso de crack na cidade de São Paulo/Brasil. Toxicodependências, v. 16, n. 2, 2010, p. 29-37.

RAUPP, Luciane Marques. Circuitos de uso de crack nas cidades de São Paulo e Porto Alegre: cotidiano, práticas e cuidado. Tese de Doutorado. Universidade de São Paulo, 2011.

RODRIGUES, N. A pátria em chuteiras: novas crônicas de futebol. São Paulo: Companhia das Letras, 1994.

RUI, Taniele. Corpos abjetos: etnografia em cenários de uso e comércio de crack. 2012. (Tese de Doutorado) - Campinas: Programa de Pós-graduação em Antropologia Social, Universidade Estadual de Campinas, 2012.

SENNET, R. O declínio do homem público: as tiranias da intimidade. São Paulo: Companhia das Letras, 1988.

SIMMEL, G. The sociology of Georg Simmel. Glencoe: The Free Press, 1950.

SILVA S. L. Mulheres da luz: uma etnografia dos usos e preservação no uso do crack. 2000. Dissertação de mestrado. São Paulo: Faculdade de Saúde Pública, Universidade de São Paulo. 2000.

. A exposição e a invisibilidade: percursos e percalços por Lisboa e São Paulo. As narrativas dos usos e dos controles do uso de crack. Tese de Doutorado. Universidade de São Paulo, 2017.

SOUZA, L. C. Notas sobre a distinção entre usuários e traficantes na "cracolândia": Apontamentos para uma crítica da política de drogas. Áskesis, v. 4, n. 1, p. 206, 2015.

VALLIM, D. C., ZALUAR, A., \& SAMPAIO, C. Uma etnografia das cenas de uso de crack no Rio de Janeiro e seus efeitos nos usuários. In: TEIXEIRA, M. FONSECA, Z. Saberes e práticas na atenção primária à saúde: cuidado à população em situação de rua e usuários de álcool, crack e outras drogas, 1. ed. São Paulo: Hucitec. 2015.

VILLELA, Jorge Luiz Mattar. Por uma Etnografia da Pelada: descrição de um caso. Pesquisa de Campo, v. 5, p. 69-93, 1997.

WEBER, M.; GERTH, H.; MILLS, C. W. From Max Weber: essays in sociology. New York: Oxford university, 1946. 
WHYTE, W. F. Sociedade de esquina: a estrutura social de uma área urbana pobre e degradada. Rio de Janeiro: Zahar, 2005.

ZINBERG, N. E. Drug, set and setting. New Haven: Yale University Press, 1984. 